\title{
0957 NEXT STEPS IN CHILD INJURY PREVENTION INCLUSION AS A PART OF CHILD SURVIVAL
}

I Scott*, J Ozanne-Smith, D Meddings Correspondence: Albany-Scott: Safety and Health Promotion, P.O. Box 7312, Mount Austin NSW 2650, Australia

\subsection{6/ip.2010.029215.957}

Introduction The World Report on Child Injury noted that over $90 \%$ of child injury deaths occur where data and health capacity are least and services and planning are swamped with excess demand. The first overarching recommendation was that child injury be integrated into a comprehensive approach to child health and development. A draft resolution on child injury will be considered by The WHO Executive Board in 2010 and will, hopefully, be adopted by the World Health Assembly in 2011. A central argument for the resolution is that child survival patterns have changed significantly and reductions in infectious disease in many places have unmasked child injury burden that was either there all along and is relatively stable (eg, drowning), or was there all along and is increasing (eg, road traffic injury). The question of how current child survival programmes, which are focused on infectious disease, can be reoriented to include injury prevention is fundamental to expanded action on child injury and the focus of this research and consultation.

Method and Discussion An informal collaboration involving agencies such as UNICEF and WHO and committed individuals will use a quasi-Delphi consultation to identify key questions in establishing child injury prevention as part of efforts on child survival. Iterative electronic consultation will be used with key informants to establish links, collect information and develop ideas on planning and priorities. A special session of the satellite biennial meeting of the International Association for Child and Adolescent Injury Prevention (ISCAIP) will discuss and amplify the results of the internet exchange.

Conclusion This is intended to (a) foster discussion on the how and what of integrating child injury prevention; (b) engage agencies and individuals and foster discussion, information exchange and collaboration; (c) facilitate identification of productive areas of work and priorities; (d) foster practical action. The results of the consultation will be presented and discussed. After any subsequent amendment they will be made available to all agencies and participants. 